\section{FREE FEATURE LECTURES AT SHOWCASE 2010}

The British Dental Trade Association is delighted to announce that there will be a feature lecture taking place before the exhibition opens on each day of Dental Showcase this year.

The one hour lectures are designed to give you an insight into the latest innovations in dentistry and are offered free of charge. Thursday's lecture, which takes place between 10am-11am, looks at the future of dentistry. Friday's lecture topic will be endodontics, while Saturday's lec- ture asks the question 'Can a new technology add a new dimension of predictability to treatment results?' The Friday and Saturday lectures both take place from 9am-10am. The time spent in all the lectures qualifies as verifiable CPD.

The lecture theatre has ample capacity to cope with demand so there is no need for advance booking. Seats will be allocated on a first come, first served basis.

Reader response number 57

\title{
WHISPER QUIET HANDPIECE IDEAL FOR LIMITED ACCESS
}

Bien-Air's Prestige range of ballbearing turbines incorporate a small head, ideal for use where access is limited or if you are performing precise and delicate work. With a long life, this whisper quiet handpiece is perfectly partnered with the Bora range.

The Bora is another incredibly quiet turbine from Bien-Air, due to the ceramic ball bearings. Already known as a workhorse, the Bora is built to last and also incorporates a triple spray diffuser.

To help infection control, both BienAir turbines are fitted with an integral non-return valve and large push buttons for easy bur removal. These turbines incorporate an anti-heat system to avoid heat build-up during treatment which may cause patient discomfort. The triple spray diffuser with three separate air and water ports ensures optimum cooling even at 315,000 rpm (Prestige) and 306,000 rpm (Bora). The Unifix quick-connect coupling means that no time is wasted when changing your handpieces.

Available with or without a light source, the Prestige and Bora turbines offer durability at economic prices.

Reader response number 58

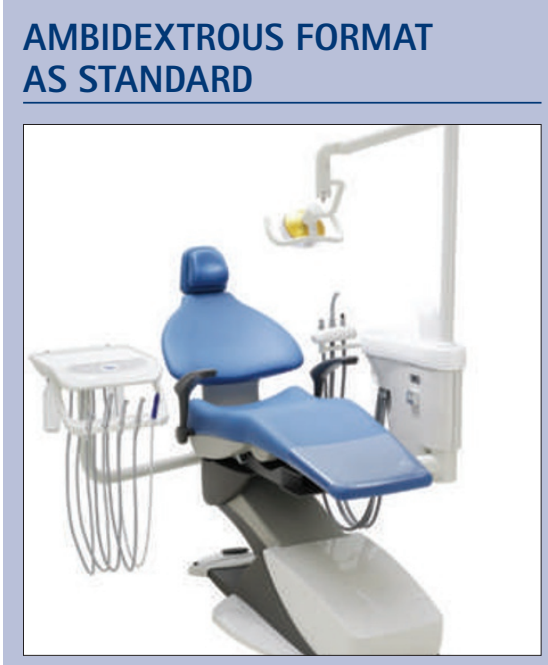

No longer do you have to compromise on price and space when choosing an ambidextrous chair unit, for the Tridac 'Contour . next' is built as standard in ambidextrous format.

Brilliantly clever by design, the 'Contour . next' chair can change from right hand to left hand use in just seconds, without the need for any tools. Compact and stylish, this chair has all internal services, so there is no requirement for those ugly utility boxes and trip hazard umbilicals. From the beautiful one-piece ceramic spittoon top to the immensely practical delivery unit, the chair just oozes quality, all achieved at a surprisingly reasonable price.

Reader response number 60

\section{ON DEMAND E-LEARNING RESOURCES}

The Dental Channel has a range of live and on-demand e-learning resources on a variety of topics.

As part of their live webinar programme for 2010, Dr S. Wilson, General Dental Practitioner and Vocational Trainer, will present a live online photography workshop on Wednesday 1 December at 8pm. Dr J. Makdissi, Senior Lecturer/Consultant in Oral and Maxillofacial Radiology will present 'Radiology' on Thursday 9 December at $1 \mathrm{pm}$. First time live webinar viewers receive a $50 \%$ discount.

The Dental Channel's on-demand webinar catalogue includes Dental
Photography (3 hrs vCPD), Radiographic Interpretation (3 hrs vCPD) and Radiography for Dental Nurses (1.5 hrs vCPD). The catalogue also includes the ergonomics resource Posture Perfect: Avoiding Back Pain (1.5 hrs vCPD). The courses are available individually or as part of a subscription package currently providing over 60 hours of verifiable CPD including core subjects for $£ 200$ + VAT.

Verifiable CPD is obtained from all courses, providing an easy and relaxed approach to keeping up to date with new knowledge and best practice in all things dental.

Reader response number 59

\section{COMPLETE TRAINING SOLUTION}

The Nobel Biocare Implantology Year Course is inviting applications to its 2010 cohort. This course is the complete training solution for any dentist wishing to practice in the exciting and rewarding field of implant dentistry.

Teaching takes place in two locations - The University of Cambridge (Churchill College) and Cavendish House Implant Centre (Cambridge). The training involves a combination of online distance learning modules, theory study days and oneto-one live surgical training.

Completing participants are awarded a 'Certificate of Competency', which demonstrates that they have received competency assessed training in accordance with the GDC requirements.

Reader response number 61 